\title{
Giant GH-secreting pituitary adenomas: management of rare and aggressive pituitary tumors
}

\author{
Ilan Shimon ${ }^{1,2}$, Raquel S Jallad ${ }^{3}$, Maria Fleseriu ${ }^{4}$, Chris G Yedinak ${ }^{4}$, \\ Yona Greenman ${ }^{2,5}$ and Marcello D Bronstein ${ }^{3}$ \\ ${ }^{1}$ Institute of Endocrinology, Rabin Medical Center, Beilinson Hospital, Petah-Tiqva 49100, Israel, \\ ${ }^{2}$ Sackler Faculty of Medicine, Tel Aviv University, Tel Aviv, Israel, ${ }^{3}$ Neuroendocrine Unit, Division of \\ Endocrinology and Metabolism, Hospital das Clínicas, University of São Paulo Medical School, São Paulo, Brazil, \\ ${ }^{4}$ Northwest Pituitary Center, Oregon Health and Science University, Portland, Oregon, USA and ${ }^{5}$ Institute of \\ Endocrinology, Metabolism and Hypertension, Tel Aviv-Sourasky Medical Center, Tel Aviv, Israel
}

Correspondence should be addressed to I Shimon

Email

ilanshi@clalit.org.il

\begin{abstract}
Objectives: Patients with acromegaly usually harbor macroadenomas measuring between 10 and 30 mm in maximal diameter. Giant (adenoma size $\geq \mathbf{4 0} \mathrm{mm}$ ) GH-secreting pituitary tumors are rarely encountered and the aim of this study is to analyze different methods for managing them.

Design and methods: We have identified 34 patients (15 men and 19 females) with giant adenomas among 762 subjects $(4.5 \%)$ with acromegaly in our records, and characterized their clinical characteristics and response to treatment. Results: Mean age at diagnosis was 34.9 \pm 12.5 years (range, 16-67 years). Mean adenoma size was $49.4 \pm 9.4 \mathrm{~mm}$ (range, 40-80 mm); 30 adenomas showed cavernous sinus invasion and 32 had suprasellar extension. Twenty-nine (85\%) patients had visual field defects. Mean baseline IGF1 was 3.4 $\pm 1.8 \times$ ULN. All patients except one underwent pituitary surgery (one to three procedures), but none achieved hormonal remission following first surgery. Among the 28 subjects with visual disturbances, 14 recovered post-operatively and 13 improved. Treatment with somatostatin analogs was given to all patients after surgical failure. Six achieved remission, nine others were partially controlled (IGF1 < $1.5 \times$ ULN; $3 / 9$ when combined with cabergoline), and 17 did not respond (two were lost). Nine patients were treated with pegvisomant, alone ( $n=4)$ or in combination with somatostatin analogs $(n=5)$; five are in remission and two are partially controlled. Pasireotide-LAR achieved hormonal remission in one of the six patients. Currently, after a mean follow-up period of 8.9 years, 17 patients are in biochemical remission, eight are partially controlled, and seven are uncontrolled (two were lost to follow-up). Conclusions: Giant GH-secreting adenomas are invasive, uncontrolled by surgery, and respond poorly to medical treatment. Aggressive multimodal therapy is critical for their management, enhancing control rate and biochemical remission.
\end{abstract}

\section{Introduction}

Acromegaly is a rare condition that usually results from a growth hormone (GH)-secreting pituitary adenoma (1). Most of these tumors (75\%) are macroadenomas ( $>10 \mathrm{~mm}$ in maximal diameter), whereas $25 \%$ are microadenomas ( $\leq 10 \mathrm{~mm}$ ). The majority of $\mathrm{GH}$-secreting tumors measure between 10 and $30 \mathrm{~mm}$, while very large tumors ( $\geq 40 \mathrm{~mm}$ ) are rarely encountered (2). These giant tumors may include atypical adenomas, but usually they
(C) 2015 European Society of Endocrinology Printed in Great Britain consist of benign tumors with no different histological characteristics compared with smaller adenomas $(3,4)$. However, sparsely granulated GH-secreting adenomas tend to be larger and more aggressive compared with densely granulated tumors, responding less to medical treatment with somatostatin analogs (5).

Giant GH-secreting adenomas usually present as invasive tumors with extrasellar extension, chiasmal

Published by Bioscientifica Ltd. 
compression, cavernous sinus invasion, and occasionally involve the clivus, the temporal lobe, the hypothalamus, and other cranial structures. These large tumors tend to prevail in young adults, usually $20-30$ years old. Albeit aggressive, these tumors are mostly benign, rarely developing into malignant pituitary carcinomas (6). Giant tumors are usually unsuitable for complete removal, thus surgery alone is not expected to achieve disease control or hormonal remission in almost all cases (2).

Owing to the rarity of giant GH-secreting pituitary tumors, information regarding their management is very sparse in the literature; hence, we have summarized a multicenter unique experience in the management of these aggressive and challenging pituitary tumors.

\section{Patients and methods}

We have identified 34 patients with giant adenomas among 762 subjects (4.5\%) with acromegaly diagnosed, treated, and followed between 1989 and 2014 in four different pituitary outpatient clinics in academic centers from Israel, Brazil, and USA. This collaborative, retrospective study included patients with acromegaly presenting with giant (adenoma size $\geq 40 \mathrm{~mm}$ ) GH-secreting pituitary tumors. The study was approved and conducted according to the local ethical institutional review boards.

Information on clinical presentation, laboratory tests including hormonal profile, pituitary imaging, and visual field assessment, at presentation and during follow-up period, were obtained from clinical records. Response to different treatment modalities and clinical improvement were also reviewed.

\section{GH and insulin-like growth factor 1 evaluation}

Serum GH and insulin-like growth factor 1 (IGF1) levels were measured in the morning following overnight fasting, using chemiluminescent immunometric assays (Immulite 2000; Siemens, Flanders, NJ, USA) in most patients. GH has a sensitivity of $0.05 \mathrm{ng} / \mathrm{ml}$. The intra-assay coefficient of variation (CV) for $\mathrm{GH}$ concentration of $3.7 \mathrm{ng} / \mathrm{ml}$ was $4.6 \%$; the corresponding inter-assay $\mathrm{CV}$ was $5.7 \%$. The intra- and inter-assay CV values for IGF1 concentration of $380 \mathrm{ng} / \mathrm{ml}$ are 2.9 and $7.4 \%$ respectively. IGF1 in Brazil was measured using Immulite 2000, or by RIA following ethanol extraction (Diagnostic Systems Laboratories, Webster, TX, USA). GH and IGF1 measurements in patients treated with pasireotide-LAR within the PAOLA study were assessed in a central laboratory (Quest Diagnostics, Madison, NJ, USA) using the Immulite 2000. IGF1 levels are presented based on the upper limit of normal range (ULN; the IGF1 value divided by the sex- and age-specific upper normal limit), comparing values among the different assays and along the years.

\section{Hormonal control}

Hormonal control was based on achieving mean or random GH levels $\leq 2.5 \mathrm{ng} / \mathrm{ml}$ and normal IGF1 for sex and age. Remission in patients treated with pegvisomant was based on normal IGF1 levels. Patients were considered partially controlled when IGF1 achieved following treatment was below $1.5 \times$ ULN.

\section{Radiological assessment}

Tumor size and extension beyond the pituitary sella at presentation and during follow-up were assessed by magnetic resonance imaging (MRI). The irregular and asymmetrical shape of most tumors resulted in an imprecise calculation of its volume. Therefore, a preoperative maximal diameter $\geq 40 \mathrm{~mm}$ was used to define a giant GH-secreting adenoma. In order to assess tumor shrinkage, MRI was performed 3-6 months following primary treatment.

\section{Histological studies}

Resected adenoma specimens were immunostained for $\mathrm{GH}$, prolactin (PRL), adrenocorticotropin, thyrotropin (TSH), as well as luteinizing hormone beta (LH $\beta)$ and follicle-stimulating hormone beta (FSH $\beta$ ).

\section{Statistical analysis}

Descriptive analysis was performed and results are expressed as mean \pm s.D.

\section{Results}

\section{Patients' characteristics at presentation}

The study cohort included 34 patients (15 males and 19 females) with giant adenomas identified among 762 subjects $(4.5 \%)$ with acromegaly in our records. Mean age at diagnosis was $34.9 \pm 12.5$ years (range, 16-67 years) (Table 1). Initial complaints leading to diagnosis included acromegalic features in 21 patients, headaches in 19 patients, and visual deterioration in 15 subjects. One patient had nasal bleeding and another was incidentally discovered. Mean adenoma size at presentation was $49.4 \pm$ $9.4 \mathrm{~mm}$ (range, $40-80 \mathrm{~mm}$ ). Twelve patients presented 
Table 1 Baseline characteristics of 34 patients with giant $\mathrm{GH}$-secreting adenomas.
Age, mean \pm s.D.

F/M

Adenoma size, mean \pm s.D.

IGF1, mean \pm s.D.

Visual field defects

Cavernous sinus involvement

Hormone co-secretion

Mean follow-up period
$34 / 762$ patients in our cohort $(4.5 \%)$

$34.9 \pm 12.5$ years

(range, 16-67 years)

$19 / 15$

$49.4 \pm 9.4 \mathrm{~mm}$

(range, 40-80 mm)

$3.4 \pm 1.8 \times$ ULN

$29 / 34$

$30 / 34$

$\mathrm{PRL}-8 ; \mathrm{TSH}-1$

$8.9 \pm 4.7$ years with tumors $\geq 50 \mathrm{~mm}$ (Table 2 ). Cavernous sinus invasion was detected in 30 out of 34 adenomas and 32 had suprasellar extension. Twenty-nine patients (85\%) had significant visual field defects, mostly bitemporal hemianopsia. Thirteen patients had random GH levels $>40 \mathrm{ng} / \mathrm{ml}$ at presentation. Maximal GH was $1261 \mathrm{ng} / \mathrm{ml}$, measured in a female with a $56 \times 47 \mathrm{~mm}$ giant tumor (patient 17, Table 2). Mean baseline IGF1 was $3.4 \pm 1.8 \times$ ULN for age. Eight patients presented with PRL-cosecretion (Table 2) and one with TSH co-secretion (patient 4), but GH was the dominant hormone secreted in all cases. Eight other patients without hyperprolactinemia or with only marginal serum PRL elevation showed PRL expression in the immunostained pituitary adenoma specimens. Data regarding pituitary cell proliferation rate (Ki-67 index) are missing for most tumors.

Five female patients were older than 45 years when diagnosed. Among the other women, all but one presented with amenorrhea, while $79 \%$ of males had hypogonadism. Twelve patients had central hypothyroidism and eight presented with secondary hypocortisolism. The clinical data of the patients are summarized in Tables 1 and 2 . Figure 1 shows MRI studies of four giant adenomas at presentation (patients 1, 2, 17, and 20).

\section{Pituitary surgery and radiotherapy}

All patients but one underwent pituitary surgery, 32 underwent transsphenoidal surgery and seven transcranial procedures, 13 underwent two to three consecutive procedures, and some had sellar operations by different approaches. Thirty-one patients underwent surgery as their first treatment approach for acromegaly. None achieved hormonal remission post-operatively. However, two out of 12 subjects are in hormonal remission following repeated surgery. Only seven patients had more than 50\% reduction in pre-operative IGF1 levels following the primary surgery. However, among the 28 subjects with pre-operative visual disturbances, 14 patients recovered, 13 improved their vision, and, in one patient, vision remained unchanged after surgery. Significant post-operative complications included cerebrospinal fluid (CSF) leak in eight patients, bacterial meningitis in two, and one patient had permanent diabetes insipidus.

Radiotherapy was given to 12 patients, including radiosurgery in two subjects. Radiotherapy was always used after surgical and/or medical treatment failure. Most patients received radiotherapy due to a large postoperative adenoma remnant. Among the patients treated with radiotherapy, only one patient achieved GH/IGF1 control 1 year following radiosurgery.

\section{Medical treatment}

Medical treatment with somatostatin analogs (octreotideLAR, $n=30$; lanreotide-Autogel, $n=7$ ) was given to most patients after surgical failure. Some patients were treated with both analogs during different periods. One patient received primary therapy with octreotide-LAR before surgery. Remission was noticed in six (five treated with octreotide-LAR $30 \mathrm{mg}$ and one with lanreotide-Autogel $90 \mathrm{mg}$ ). Nine others were partially controlled (IGF1 $<1.5 \times$ ULN), while treated with octreotide-LAR (3/9 when combined with cabergoline, $3.5 \mathrm{mg} /$ week); and $17 \mathrm{did}$ not respond (two were lost to follow-up) (Fig. 2). Mean treatment duration with octreotide-LAR was $5.6 \pm 3.8$ years (median, 6 years), and $3.5 \pm 3$ (median, 3 years) with lanreotide-Autogel. Cabergoline as a primary treatment (before surgery or somatostatin analog) was initiated in two patients who did not respond. Cabergoline (3.5 mg/week) when added to nine patients, uncontrolled while on octreotide-LAR, brought three patients (33\%) into partial control (IGF1<1.5 ×ULN) (Fig. 2).

Nine patients were treated with pegvisomant (not yet available in the public health system in Brazil), either alone $(n=4)$, or in combination with octreotide-LAR or lanreotideAutogel $(n=5)$, for a mean period of $3.3 \pm 1.8$ years (median, 4 years). Remission was achieved in five subjects (combination treatment in four), partial control (IGF1 $<1.5 \times \mathrm{ULN}$ ) was noticed in additional two subjects (one female patient is now in remission following the addition of contraceptive pills to her regimen, patient 5 , Table 2 ), one patient responded poorly to pegvisomant (30 mg/day) treatment, and one discontinued treatment due to intolerance.

Six of the patients in our cohort were treated with pasireotide-LAR $60 \mathrm{mg} / 4$ weeks within the multicenter 
Table 2 Baseline characteristics and response to treatment of each patient in the cohort.

\begin{tabular}{|c|c|c|c|c|c|c|c|c|c|c|c|}
\hline & $\begin{array}{c}\text { Age } \\
\text { (years) }\end{array}$ & Sex & $\begin{array}{c}\text { Tumor } \\
\text { size }(\mathrm{mm})\end{array}$ & $\begin{array}{l}\text { Visual } \\
\text { defect }\end{array}$ & $\begin{array}{c}\text { IGF1 } \times \\
\text { ULN }\end{array}$ & $\begin{array}{c}\text { PRL } \\
(\mathrm{ng} / \mathrm{ml})\end{array}$ & Surgery & $\begin{array}{l}\text { FSR/RS F/U } \\
\text { (years) }\end{array}$ & $\begin{array}{c}\mathbf{F} / \mathbf{U} \\
\text { (years) }\end{array}$ & Remission with & $\begin{array}{l}\text { Current tumor } \\
\text { size }(\mathrm{mm})\end{array}$ \\
\hline 1 & 20 & $M$ & 60 & - & 2.5 & $164^{a}$ & TC, TSS & RS-10 & 14 & RS & 18 \\
\hline 2 & 44 & $\mathrm{M}$ & 50 & + & 2.5 & 65 & TSS & & 15 & & 23 \\
\hline 3 & 21 & $\mathrm{M}$ & 45 & + & 2.5 & 32 & TSS & & 7 & & 30 \\
\hline 4 & 33 & $\mathrm{~F}$ & 41 & + & NA & 7 & TSS & & 10 & Octreotide & Small remnant \\
\hline 5 & 27 & $\mathrm{~F}$ & 45 & - & 4 & 6 & TSS & FSR-1.1 & 2.5 & $P E G+E_{2}$ & 31 \\
\hline 6 & 33 & $\mathrm{M}$ & 40 & - & 4 & $54^{a}$ & TSS & & 1.5 & Octreotide & 26 \\
\hline 7 & 67 & $\mathrm{M}$ & 55 & + & 1.3 & 43 & TSS, TC & & 9 & Lanreotide & 29 \\
\hline 8 & 19 & $\mathrm{M}$ & 43 & - & 2.3 & $475^{a}$ & TSS & & 3.5 & Octreotide + PEG & 12 \\
\hline 9 & 36 & $\mathrm{~F}$ & 70 & + & NA & NA & TSS & & & No follow-up & NA \\
\hline 10 & 22 & $\mathrm{~F}$ & 45 & + & 2.35 & $173^{a}$ & TSS & RS-15 & 16 & Octreotide $+E_{2}$ & 26 \\
\hline 11 & 25 & $\mathrm{M}$ & 40 & + & 2.6 & 28 & TSS & FSR-11 & 19 & PEG & $\begin{array}{c}\text { No visible } \\
\text { tumor }\end{array}$ \\
\hline 12 & 35 & $\mathrm{~F}$ & 45 & - & 2.5 & NA & TSS & FSR-12 & 13 & & 10 \\
\hline 13 & 34 & $F$ & 45 & + & 1.5 & 40 & TSS & & 7 & Octreotide & NA \\
\hline 14 & 50 & $\mathrm{~F}$ & 45 & + & 3.2 & $85^{a}$ & TSS & & 12 & Octreotide & 26 \\
\hline 15 & 37 & $\mathrm{~F}$ & 47 & + & 8.3 & 11 & TSS & & 9 & & 28 \\
\hline 16 & 32 & $\mathrm{~F}$ & 40 & + & 4.5 & 25 & TSS & & 5 & & 21 \\
\hline 17 & 49 & $\mathrm{~F}$ & 56 & + & 4.6 & $324^{a}$ & TSS & & 4 & & 38 \\
\hline 18 & 49 & $\mathrm{~F}$ & 51 & + & 7 & $322^{a}$ & TC, TSS & Con-9 & 10 & & 25 \\
\hline 19 & 28 & $\mathrm{~F}$ & 46 & + & 3.4 & 38 & $\mathrm{TSS} \times 2$ & FSR-8 & 11 & & 31 \\
\hline 20 & 47 & $F$ & 70 & + & 4.6 & $3600^{a}$ & None & & 6 & & 40 \\
\hline 21 & 33 & $\mathrm{~F}$ & 80 & + & 8.4 & 8 & TC, TSS & & 13 & & 41 \\
\hline 22 & 36 & $\mathrm{~F}$ & 47 & + & 3.7 & 25 & $\mathrm{TSS} \times 2$ & & 9 & Pasireotide & 18 \\
\hline 23 & 38 & $\mathrm{M}$ & 49 & + & 2.5 & 50 & TSS $\times 2$ & & 8 & & 26 \\
\hline 24 & 16 & $\mathrm{~F}$ & 45 & + & NA & 26 & $\mathrm{TC}$ & Con, FSR-14 & 20 & & 28 \\
\hline 25 & 33 & $\mathrm{~F}$ & 42 & + & 1.1 & 44 & $\mathrm{TC}, \mathrm{TSS} \times 2$ & FSR-12 & 13 & Octreotide & 18 \\
\hline 26 & 33 & $\mathrm{M}$ & 48 & + & 3.9 & 5 & TSS & & 10 & & 10 \\
\hline 27 & 26 & $\mathrm{~F}$ & 45 & + & 4.1 & 19 & TSS & & 9 & & 34 \\
\hline 28 & 55 & $\mathrm{M}$ & 43 & + & 1.9 & 19 & TSS $\times 2$ & & 8 & $\begin{array}{r}\text { Repeated } \\
\text { surgery }\end{array}$ & 11 \\
\hline 29 & 19 & $\mathrm{M}$ & 60 & + & 2.6 & 30 & TSS & Con-6 & 7 & Lanreotide + PEG & 5 \\
\hline 30 & 60 & $\mathrm{M}$ & 55 & + & 2.3 & 30 & $\mathrm{TSS} \times 2$ & & 1.5 & $\begin{array}{r}\text { Repeated } \\
\text { surgery }\end{array}$ & 11 \\
\hline 31 & 49 & $\mathrm{~F}$ & 45 & + & 2.9 & 40 & $\mathrm{TSS} \times 2 \mathrm{TC}$ & Con-7 & 8 & Octreotide + PEG & 9 \\
\hline 32 & 33 & $\mathrm{M}$ & 52 & + & 1.6 & 26 & $\mathrm{TSS} \times 2$ & Con-6 & 7 & Octreotide + PEG & 26 \\
\hline 33 & 20 & $\mathrm{M}$ & 40 & + & 2.8 & 12 & TSS $\times 2$ & & 2.5 & & 8 \\
\hline 34 & 29 & $M$ & 50 & + & 3.3 & 17 & TSS & & 1.5 & No follow-up & 10 \\
\hline
\end{tabular}

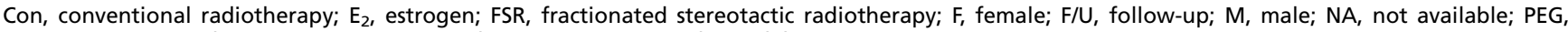
pegvisomant; RS, radiosurgery; TC, transcranial surgery; TSS, transsphenoidal surgery. ${ }^{\text {aPRL }}$ co-secretion.

PAOLA phase III study for patients with inadequately controlled acromegaly, despite receiving high-dose somatostatin analogs (Novartis Pharma AG) (7). Five patients had baseline IGF1 $>2 \times$ ULN before pasireotide administration, and, in one patient, it was measured between 1.5 and $2 \times \mathrm{ULN}$. After a mean treatment period of $3.3 \pm 0.3$ years (median, 3.5 years), one of these patients (one of six patients; 17\%) was in remission with pasireotide-LAR $60 \mathrm{mg}$, two others were partially controlled (IGF1 $<1.5 \times \mathrm{ULN}$ ), and the other three were uncontrolled. Pasireotide-LAR has been previously given to medically naïve patients with active acromegaly within the CSOM230C2305 phase III study (Novartis) (8).

Currently, after a mean follow-up period of $8.9 \pm 4.7$ years (median, 9 years; range, 1.5-19 years), 17 patients are in biochemical remission, eight are partially controlled, and seven remained uncontrolled. Two patients were lost to follow-up. Last follow-up mean maximal diameter of adenoma remnants assessed by MRI is $21.6 \pm 10.6 \mathrm{~mm}$ (Table 2). These results were achieved after exposure to multiple treatment modalities including surgery, radiotherapy, and medical therapies with somatostatin analogs, cabergoline, and pegvisomant (mean, 3.8 modalities/patient). Patients in remission ( $n=17$ ) achieved biochemical (IGF1) control with repeated surgery $(n=2)$, radiosurgery $(n=1)$, somatostatin analogs (octreotide and lanreotide) $(n=6)$, pasireotide $(n=1)$, pegvisomant $(n=1)$, somatostatin analog with pegvisomant $(n=4)$, pegvisomant with estrogen $(n=1)$, and somatostatin analog with estrogen $(n=1)$. 
20-year-old male (patient 1)

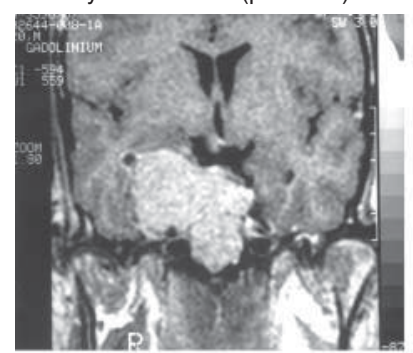

49-year-old female (patient 17)

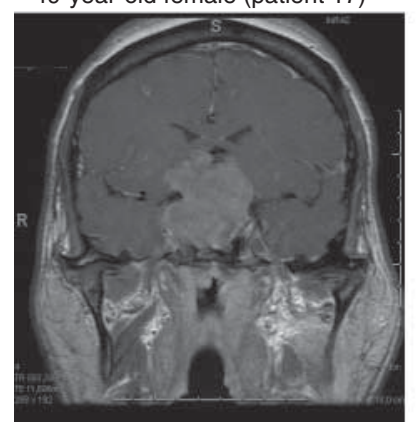

44-year-old male (patient 2)

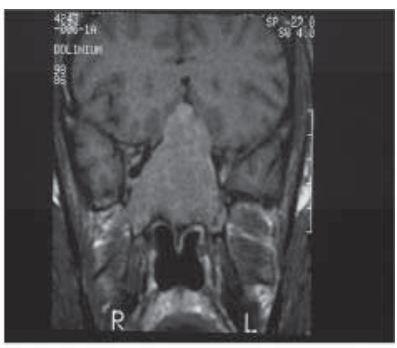

47-year-old female (patient 20)

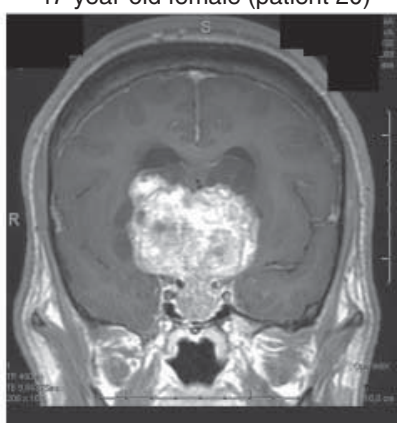

\section{Figure 1}

Coronal MRI T1-weighted sequence, gadolinium enhanced, of four patients with giant $\mathrm{GH}$-secreting adenomas at presentation.

\section{Discussion}

Acromegaly is a rare disorder usually caused by GH hypersecretion from a GH-producing pituitary adenoma.

Most affected subjects harbor macroadenomas, but it is estimated that $<5 \%$ of these grow to very large sizes of $\geq 40 \mathrm{~mm}$ in diameter to become gigantic tumors. As these adenomas are rare, only anecdotal case reports of patients diagnosed with giant GH-secreting pituitary adenomas were reported $(9,10,11,12)$, whereas no published cohorts devoted only to patients with very large somatotroph tumors are available in the literature. In a large consecutive series of 668 patients with acromegaly referred for pituitary surgery, only ten giant tumors were included (1.5\%) (2). We have identified and summarized a large series of 34 patients diagnosed with giant GH-secreting cell adenomas representing $4.5 \%$ of the acromegalic patients in four large pituitary clinical centers. However, this may overestimate the true proportion of those aggressive tumors, as all participating pituitary clinics are tertiary centers. This unique cohort of rare GH-secreting tumors illustrates the difficulties encountered in achieving biochemical control of acromegaly and relieving tumor mass effects in these patients.

Transsphenoidal adenoma resection is the preferred first-line treatment modality for patients with acromegaly.
Microadenomas and intrasellar macroadenomas are reported to have a relatively high remission rate, 60-80\% $(2,13,14,15,16)$. With increasing adenoma size and invasiveness beyond the sellar boundaries, remission rate gradually decreases $(2,13,17,18)$ and reach almost $0 \%$ for giant GH-secreting cell tumors (2), similarly to the surgical results observed for patients included in this study. Importantly, patients in our series were operated by wellexperienced pituitary neurosurgeons, some with reported post-operative remission rate of $\sim 60 \%$ for $\mathrm{GH}$-secreting macroadenomas (13). However, patients with very large adenomas still can benefit from a pituitary operation that relieves chiasmal compression and can improve the subsequent response to medical treatment with somatostatin analogs after partial tumor debulking $(19,20,21)$. Repeated surgery resulted in hormonal remission in two patients. Prior surgery also may decrease the radiation exposure to the optic pathways following tumor volume reduction if radiation is planned. However, after surgical failure, only one of the 12 patients with giant tumor, who were referred for radiotherapy, achieved hormonal remission. This is in contrast to the reported rate of $50-60 \%$ of GH-IGF1 normalization following radiotherapy for smaller GH-secreting adenomas $(22,23)$. Thus, in the short term, pituitary surgery followed by radiotherapy is not efficacious as the only approach for these aggressive adenomas.

The depot somatostatin analogs, octreotide-LAR, and lanreotide-Autogel are considered as the preferred first-line pharmacological treatment for patients with active acromegaly $(24,25)$, either as a primary treatment $(26,27)$ or as an adjuvant therapy following unsuccessful pituitary surgery. Normalization of GH and IGF1 is achieved in 50-60\% of

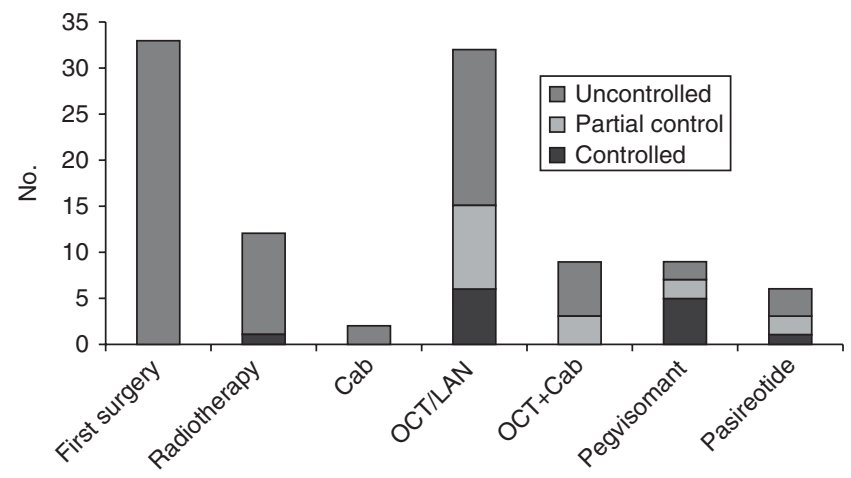

\section{Figure 2}

Number of patients with giant GH-secreting adenomas achieving biochemical control or partial control with different treatment modalities available for acromegaly. Cab, cabergoline; OCT, octreotide-LAR; LAN, lanreotide-Autogel. 
patients treated as primary or secondary therapy. The efficacy rate may be improved by surgical debulking of large macroadenomas $(19,20,21)$. Only six out of 32 patients in our cohort (19\%), treated with the commercially available analogs octreotide-LAR or lanreotide-Autogel, achieved biochemical remission, whereas nine others were partially controlled. This remission rate is far below the rate considered appropriate for patients harboring GH-secreting macroadenomas (28). It has been shown that baseline or pretreatment GH levels inversely correlated with the chance to achieve GH and IGF1 control with somatostatin analogs, although absolute greater GH suppression is achieved when tumors with higher baseline GH are treated medically (29). Moreover, aggressive GH tumors show low p21 (CDKN1A) and SSTR2 expression that results in decreased responsiveness to medical treatment (30). This may explain why our patients with giant tumors and high GH and IGF1 secretion poorly responded to somatostatin analogs, although the response rate might be improved somehow after partial adenoma resection, or with the addition of cabergoline (31), as shown in three out of nine patients on octreotide-LAR monotherapy who became partially controlled when cabergoline was added as co-treatment. Importantly, six of our patients were referred to treatment with pasireotide-LAR, the second-generation multireceptor-targeted somatostatin analog, developed by Novartis Pharma AG and given as monthly injection, within a large multicenter phase III study (PAOLA) for patients with inadequately controlled acromegaly, previously treated with high-dose somatostatin analogs (7). One out of six (17\%) achieved hormonal control and two others were partial responders. Pasireotide with its higher affinity for $s t_{5}$ has shown superior efficacy in providing biochemical control over the first-generation somatostatin analogs both in medically naïve patients with acromegaly (8) and in patients with inadequately controlled acromegaly despite receiving somatostatin analogs (7). The response rate to pasireotide-LAR in our patients with giant adenomas (17\%) was compatible with the 15 and $20 \%$ control rate reported in the PAOLA study for patients receiving the 40 and $60 \mathrm{mg}$ monthly injections respectively (7). This novel analog has been approved recently in Europe and the USA for treating patients with inadequately controlled acromegaly.

Five of our patients (out of nine), who were not in biochemical remission, achieved IGF1 control when switched to pegvisomant treatment, either alone or as part of a combination treatment. However, as pegvisomant is not available in the public health system of Brazil, almost half of the patients included in the cohort were not suitable for this therapeutic option. As pegvisomant has no effect on tumor shrinkage, combination medical treatment may be beneficial in these patients to relieve tumor mass effects.

Other options in the therapeutic armamentarium for patients with aggressive tumors resistant to the currently available medical treatments include the alkylating agent temozolomide that may be effective for aggressive pituitary tumors and pituitary carcinomas $(32,33)$ resistant to the conventional treatments.

Our cohort of giant pituitary somatotroph adenomas emphasize the poor response these patients show to surgery, radiotherapy, or medical therapy. However, an aggressive multimodal management strategy has a reasonable likelihood to achieve disease control in these challenging patients.

\section{Declaration of interest}

I Shimon has received research grants, and consulting and lectureship fees from Novartis and Pfizer, and participated in the PAOLA study. M Fleseriu received research support to OHSU from Novartis, Pfizer, and Ipsen, and scientific consulting fees from Novartis and Pfizer. $Y$ Greenman received research grant from Pfizer, and research grant, travel support, and speaker fees from Novartis. M D Bronstein is a speaker for Ipsen and Novartis, a member of steering committees for Chiasma, Ipsen, and Novartis, and participated in the Paola study.

\section{Funding}

This research did not receive any specific grant from any funding agency in the public, commercial or not-for-profit sector.

\section{References}

1 Melmed S. Acromegaly pathogenesis and treatment. Journal of Clinical Investigation 2009119 3189-3202. (doi:10.1172/JCI39375)

2 Nomikos P, Buchfelder M \& Fahlbusch R. The outcome of surgery in 668 patients with acromegaly using current criteria of biochemical 'cure'. European Journal of Endocrinology 2005152 379-387. (doi:10.1530/eje.1. 01863)

3 Zada G, Woodmansee WW, Ramkissoon S, Amadio J, Nose V \& Laws ER Jr. Atypical pituitary adenomas: incidence, clinical characteristics, and implications. Journal of Neurosurgery 2011114 336-344. (doi:10.3171/2010.8.JNS10290)

4 Chacko G, Chacko AG, Lombardero M, Mani S, Seshadri MS, Kovacs K \& Scheithauer BW. Clinicopathologic correlates of giant pituitary adenomas. Journal of Clinical Neuroscience 200916 660-665. (doi:10.1016/j.jocn.2008.08.018)

5 Brzana J, Yedinak CG, Gultekin SH, Delashaw JB \& Fleseriu M. Growth hormone granulation pattern and somatostatin receptor subtype $2 \mathrm{~A}$ correlate with postoperative somatostatin receptor ligand response in acromegaly: a large single center experience. Pituitary 201316 490-498. (doi:10.1007/s11102-012-0445-1)

6 Tanaka T, Kato N, Aoki K, Watanabe M, Arai T, Hasegawa Y \& Abe T. Long-term follow-up of growth hormone-producing pituitary carcinoma with multiple spinal metastases following multiple surgeries: case report. Neurologia Medico-Chirurgica 201353 707-711. (doi:10.2176/ nmc.cr2012-0152) 
7 Gadelha MR, Bronstein MD, Brue T, Coculescu M, Fleseriu M, Guitelman M, Pronin V, Raverot G, Shimon I, KodamaLievre K et al. Pasireotide versus continued treatment with octreotideor lanreotide in patients with inadequately controlled acromegaly (PAOLA): a randomised, phase 3 trial. Lancet. Diabetes \& Endocrinology 20142 875-884. (doi:10.1016/S2213-8587(14)70169-X)

8 Colao A, Bronstein MD, Freda P, Gu F, Shen CC, Gadelha M, Fleseriu M, van der Lely AJ, Farrall AJ, Hermosillo Reséndiz K et al. Pasireotide versus octreotide in acromegaly: a head-to-head superiority study. Journal of Clinical Endocrinology and Metabolism 201499 791-799. (doi:10.1210/jc.2013-2480)

9 Cahyanur R, Setyawan W, Sudrajat DG, Setyowati S, Purnamasari D \& Soewondo P. Diagnosis and management of acromegaly: giant invasive adenoma. Acta Medica Indonesiana 201143 122-128.

10 Ip TP, Chan FL, Kung AW \& Lam KS. Giant growth-hormone secreting pituitary tumour with extracranial extension. Australasian Radiology 199640 88-90. (doi:10.1111/j.1440-1673.1996.tb00355.x)

11 Ravikiran M, Anil Bhansali A, Dutta P, Singh P, Mukherjee KK \& Walia R. Giant somatotropinoma. BMJ Case Reports 200921483. (doi:10.1136/bcr.01.2009.1483)

12 Sidhaye A, Burger P, Rigamonti D \& Salvatori R. Giant somatotrophinoma without acromegalic features: more "quiet" than "silent": case report. Neurosurgery 200556 E1154.

13 Shimon I, Cohen ZR, Ram Z \& Hadani M. Transsphenoidal surgery for acromegaly: endocrinological follow-up of 98 patients. Neurosurgery 200148 1239-1243.

14 Hazer DB, Işık S, Berker D, Güler S, Gürlek A, Yücel T \& Berker M. Treatment of acromegaly by endoscopic transsphenoidal surgery: surgical experience in 214 cases and cure rates according to current consensus criteria. Journal of Neurosurgery 2013119 1467-1477. (doi:10.3171/2013.8.JNS13224)

15 Starke RM, Raper DM, Payne SC, Vance ML, Oldfield EH \& Jane JA Jr. Endoscopic vs microsurgical transsphenoidal surgery for acromegaly: outcomes in a concurrent series of patients using modern criteria for remission. Journal of Clinical Endocrinology and Metabolism 201398 3190-3198. (doi:10.1210/jc.2013-1036)

16 Wang YY, Higham C, Kearney T, Davis JR, Trainer P \& Gnanalingham KK. Acromegaly surgery in Manchester revisited - the impact of reducing surgeon numbers and the 2010 consensus guidelines for disease remission. Clinical Endocrinology 201276 399-406. (doi:10.1111/j.1365-2265.2011.04193.x)

17 Jane JA Jr, Starke RM, Elzoghby MA, Reames DL, Payne SC, Thorner MO, Marshall JC, Laws ER Jr \& Vance ML. Endoscopic transsphenoidal surgery for acromegaly: remission using modern criteria, complications, and predictors of outcome. Journal of Clinical Endocrinology and Metabolism 201196 2732-2740. (doi:10.1210/jc.2011-0554)

18 Shirvani M \& Motiei-Langroudi R. Transsphenoidal surgery for growth hormone-secreting pituitary adenomas in 130 patients. World Neurosurgery 201481 125-130. (doi:10.1016/j.wneu.2013.01.021)

19 Petrossians P, Borges-Martins L, Espinoza C, Daly A, Betea D, Valdes-Socin H, Stevenaert A, Chanson P \& Beckers A. Gross total resection or debulking of pituitary adenomas improves hormonal control of acromegaly by somatostatin analogs. European Journal of Endocrinology 2005152 61-66. (doi:10.1530/eje.1.01824)

20 Colao A, Attanasio R, Pivonello R, Cappabianca P, Cavallo LM, Lasio G, Lodrini A, Lombardi G \& Cozzi R. Partial surgical removal of growth hormone-secreting pituitary tumors enhances the response to somatostatin analogs in acromegaly. Journal of Clinical Endocrinology and Metabolism 200691 85-92. (doi:10.1210/jc.2005-1208)
21 Jallad RS, Musolino NR, Kodaira S, Cescato VA \& Bronstein MD. Does partial surgical tumour removal influence the response to octreotideLAR in acromegalic patients previously resistant to the somatostatin analogue? Clinical Endocrinology 200767 310-315. (doi:10.1111/j. 1365-2265.2007.02885.x)

22 Jezková J, Marek J, Hána V, Krsek M, Weiss V, Vladyka V, Lisák R, Vymazal J \& Pecen L. Gamma knife radiosurgery for acromegaly long-term experience. Clinical Endocrinology 200664 588-595.

23 Lee CC, Vance ML, Xu Z, Yen CP, Schlesinger D, Dodson B \& Sheehan J. Stereotactic radiosurgery for acromegaly. Journal of Clinical Endocrinology and Metabolism 201499 1273-1281. (doi:10.1210/jc.2013-3743)

24 Giustina A, Chanson P, Kleinberg D, Bronstein MD, Clemmons DR, Klibanski A, van der Lely AJ, Strasburger CJ, Lamberts SW, Ho KK et al. Expert consensus document: a consensus on the medical treatment of acromegaly. Nature Reviews. Endocrinology 201410 243-248. (doi:10.1038/nrendo.2014.21)

25 Jallad RS, Musolino NR, Salgado LR \& Bronstein MD. Treatment of acromegaly with octreotide-LAR: extensive experience in a Brazilian institution. Clinical Endocrinology 200563 168-175. (doi:10.1111/ j.1365-2265.2005.02317.x)

26 Caron PJ, Bevan JS, Petersenn S, Flanagan D, Tabarin A, Prévost G, Maisonobe P, Clermont A \& PRIMARYS Investigators. Tumor shrinkage with lanreotide Autogel $120 \mathrm{mg}$ as primary therapy in acromegaly: results of a prospective multicenter clinical trial. Journal of Clinical Endocrinology and Metabolism 201499 1282-1290. (doi:10.1210/jc.2013-3318)

27 Bevan JS, Atkin SL, Atkinson AB, Bouloux PM, Hanna F, Harris PE, James RA, McConnell M, Roberts GA, Scanlon MF et al. Primary medical therapy for acromegaly: an open, prospective, multicenter study of the effects of subcutaneous and intramuscular slow-release octreotide on growth hormone, insulin-like growth factor-I, and tumor size. Journal of Clinical Endocrinology and Metabolism 200287 4554-4563. (doi:10.1210/ jc.2001-012012)

28 Cozzi R, Montini M, Attanasio R, Albizzi M, Lasio G, Lodrini S, Doneda P, Cortesi L \& Pagani G. Primary treatment of acromegaly with octreotide LAR: a long-term (up to nine years) prospective study of its efficacy in the control of disease activity and tumor shrinkage. Journal of Clinical Endocrinology and Metabolism 200691 1397-1403. (doi:10.1210/ jc.2005-2347)

29 Howlett TA, Willis D, Walker G, Wass JA, Trainer PJ \& UK Acromegaly Register Study Group (UKAR-3). Control of growth hormone and IGF1 in patients with acromegaly in the UK: responses to medical treatment with somatostatin analogues and dopamine agonists. Clinical Endocrinology 201379 689-699. (doi:10.1111/cen.12207)

30 Cuevas-Ramos D, Carmichael JD, Cooper O, Bonert VS, Gertych A, Mamelak AN \& Melmed S. A structural and functional acromegaly classification. Journal of Clinical Endocrinology and Metabolism 2015100 122-131.

31 Jallad RS \& Bronstein MD. Optimizing medical therapy of acromegaly: beneficial effects of cabergoline in patients uncontrolled with longacting release octreotide. Neuroendocrinology 200990 82-92. (doi:10.1159/000218323)

32 Vieira Neto L, Chimelli L, Pereira PJ, Gasparetto EL, Bines J, Wildemberg LE $\&$ Gadelha MR. The role of temozolomide in the treatment of a patient with a pure silent pituitary somatotroph carcinoma. Endocrine Practice 201319 145-149. (doi:10.4158/EP12400.CR)

33 Raverot G, Castinetti F, Jouanneau E, Morange I, Figarella-Branger D, Dufour H, Trouillas J \& Brue T. Pituitary carcinomas and aggressive pituitary tumours: merits and pitfalls of temozolomide treatment. Clinical Endocrinology 201276 769-775. (doi:10.1111/j.1365-2265. 2012.04381.x)

Received 16 December 2014

Revised version received 10 February 2015

Accepted 10 March 2015 